\title{
Commentary: There's more to life than just plain M\&Ms
}

\author{
John N. Dentel, MD, ${ }^{a}$ and Henry L. Walters III, MD ${ }^{\mathrm{a}, \mathrm{b}}$
}

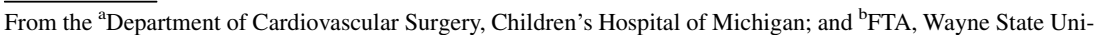 \\ versity School of Medicine, Detroit, Mich. \\ Disclosures: Authors have nothing to disclose with regard to commercial support. \\ Received for publication Sept 10, 2019; revisions received Sept 10, 2019; accepted for publication Sept 10, 2019; \\ available ahead of print Oct 21, 2019. \\ Address for reprints: John N. Dentel, MD, Department of Cardiovascular Surgery, Children's Hospital of Mich- \\ igan, 3901 Beaubien Blvd, Detroit, MI 48201 (E-mail: jdentel@dmc.org). \\ J Thorac Cardiovasc Surg 2020;159:615-6 \\ $0022-5223 / \$ 36.00$ \\ Copyright (C) 2019 Published by Elsevier Inc. on behalf of The American Association for Thoracic Surgery \\ https://doi.org/10.1016/j.jtcvs.2019.09.018
}

Advancements in medical knowledge and surgical techniques have drastically changed the landscape of congenital heart disease (CHD). As a result, there are more adults living with CHD than pediatric patients. ${ }^{1}$ Analyzing the short-term morbidity and mortality (M\&M) of this everincreasing population of survivors is no longer sufficient. Rather, we must also understand their long-term functional health status (FHS). FHS is "an individual's ability to perform normal daily activities required to meet basic needs, fulfill usual roles, and maintain health and well-being." 2 Understanding the FHS of adults living with CHD will allow health care providers to deliver more appropriate care and ultimately, improve patients' quality of life.

Jegatheeswaran and colleagues ${ }^{3}$ explored the FHS of postoperative patients with d-transposition of the great arteries (d-TGA) who have transitioned into adulthood. In general, the survey responses demonstrate that the FHS in this cohort is the same or even better than their agematched normal population. This finding is comparable with other studies of FHS in postoperative patients with CHD. ${ }^{4,5}$

As encouraging as these outcomes are, there are areas for improved understanding. It is concerning that an increasing number of patients indicated that their health status is at least somewhat worse than the previous year. Furthermore, the Pediatric Quality of Life Inventory survey results revealed a significantly reduced physical functioning score in patients with d-TGA compared with their healthy peers. Understanding the impact of this trend in the general health status and physical functioning of patients with d-TGA will aid in providing more informed care to these patients.

The authors suggest that the negative changes in selfperceived general health status are related to an increased perception of their own limitations. In addition, this perceived decline could conceivably be related to the transition into adulthood, since the responders are faced with new challenges, including independence, self-reliance, and transition of care. Examples of barriers to the transition to adult care include an attachment to a pediatric clinician or

\section{References} 2, 2019.

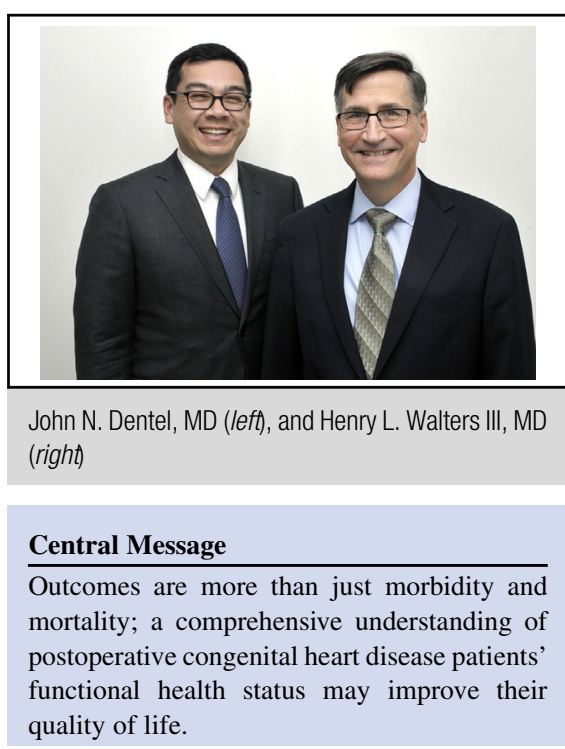

See Article page 604.

institution, noncompliance, and anxiety related to independent decision making. ${ }^{6}$ These obstacles may delay patients from pursuing consistent care by an adult CHD provider, potentially compromising overall health and well-being.

This study used generalized surveys designed to determine an individual's perceived health. These generic questionnaires allow for the analysis of cohorts compared with normalized reference populations. However, they are less sensitive and unlikely to detect clinically important differences, as they fail to focus on the unique aspects of CHD. The development of a CHD-specific survey would theoretically be more sensitive in detecting small differences, leading to improved, more individualized care.

As evidenced by Jegatheeswaran and colleagues, postoperative patients with d-TGA can reasonably anticipate a normal FHS as they transition into adulthood. ${ }^{3}$ The outcomes for patients with CHD consist of more than just M\&Ms; they must include FHS. The self-perceived decline in general health status and physical functioning is likely multifactorial. With the design and use of CHD-specific surveys, we will be able to accurately provide more informed and comprehensive health care.

1. American Academy of Pediatrics. Congenital heart public health consortium. Available at: https://aap.org/en-us/advocacy-and-policy/aap-health-initiatives/ chphc/pages/fact-sheet.aspx. Accessed September 6, 2019.

2. American Thoracic Society. Quality of life resource. Available at: https://qol thoracic.org/sections/key-concepts/functional-status.html. Accessed September 
3. Jegatheeswaran A, Devlin PJ, DeCampli WM, Welke KF, Williams WG, Blackstone $\mathrm{EH}$, et al. Longitudinal functional health status in young adults with repaired dextro-transposition of the great arteries: a Congenital Heart Surgeons' Society study. J Thorac Cardiovasc Surg. 2020;159: 604-14.e3.

4. Jegatheeswaran A, Jacobs ML, Caldarone CA, Kirshbom PM, Williams WG, Blackstone EH, et al. Self-reported functional health status following interrupted aortic arch repair: a Congenital Heart Surgeons' Society Study. J Thorac Cardiovasc Surg. 2019;157:1577-87.e10.

5. Knowles R, Veldtman G, Hickey EJ, Bradley T, Gengsakul A, Webb GD, et al. Functional health status of adults with tetralogy of Fallot: matched comparison with health siblings. Ann Thorac Surg. 2012;94:124-32.

6. Lee A, Bailey B, Cullen-Dean G, Aiello S, Morin J, Oechslin E. Transition of care in congenital heart disease: ensuring the proper handoff. Curr Cardiol Rep. 2017;19:55. 